\title{
Um olhar sobre as construções \\ de identidades de gênero \\ na contemporaneidade ${ }^{1}$
}

Resumo

Esta pesquisa é uma intenção de refletir sobre as construções de gênero e de identidade sexual em um grupo de pessoas com sexualidade cotidiana não-normativa. Nessa direção, este projeto também quis pensar a diversidade na produção de subjetivações apontando para a variedade de tecnologias do "eu" e de gênero, sustentando minhas observações e reflexões baseada no conceito construcionista, nos estudos culturais e na teoria queer.

1. Esta pesquisa é parte integrante do programa de pós-graduaçao: "Artes Visuais y Educación: un enfoque construccionista, da Universitat de Barcelona, e tem como orientadora a profa. dra. Maria Montserrat Rifà Valls, da Universitat Autonoma de Barcelona.

Palavras-chave: Identidade, gênero, heteronormatividade 


\begin{abstract}
This research is intended to observe the gender construction and sexual identity in a group of people with a non standard sexuality in a daily basis. Into this direction this project is also meant to think the diversity on the subjectivities production pointing to a variety of 'technologies of the self', sustaining my observations and reflections based on the construcionism perspective, cultural studies and the queer theory.
\end{abstract}


As últimas décadas foram palco de importantes mudanças nas práticas de subjetividades das sexualidades e nos modos de vivê-las. Atualmente, a diversidade sexual e de gênero é uma característica que podemos observar em toda sorte de encontros e desencontros entre as pessoas e isso vem desestabilizando as noções herdadas e culturalmente reproduzidas sobre gênero e sexualidade. Trata-se de uma profunda e inconclusa transformação nos modos de pensar conceitos como feminino e masculino, a normalidade e a anormalidade.

O conceito de gênero, introduzido pelas teóricas feministas na década de 7o, colaborou para ampliar o entendimento das sexualidades e suas representações binárias para além do discurso historicamente construído em que gênero era compreendido apenas como uma questão biológica dos sexos. Como afirma Judith Butler, gênero não pode ser entendido como um conjunto de atributos vagos e desconectados, uma vez que é produzido performativamente. (BUTLER, 2001, p.84). Desta forma, agora é necessário levar em consideração os diferentes grupos sociais e os distintos momentos históricos, distanciando-se das preposições essencialistas e excludentes em que o sexo biológico é diretamente ligado à questão da identidade de gênero.

A atualidade exige pensar em múltiplas maneiras de ver o mundo, de ser e de estar, observando a pluralidade das representações de identidades sexuais, pois os pilares construídos pela heteronormatividade não são fixos e nem tampouco imutáveis. Mas a sociedade ainda dá sinais de ter dificuldades de conviver com a diversidade e muitos preconceitos ainda persistem.

A complexidade dessas resistências implica que, para algumas pessoas, a confirmação e aceitação de suas sexualidades seja um processo problemático, tanto pela própria dificuldade de assumirem-se, como também pela reação do entorno. Apesar dos processos de autodescobrimento e autoconstrução darem-se no terreno do individual e das subjetividades, é no espaço social onde ocorrem os encontros e onde se passa a vida, porque é no encontro com o outro que nos formamos como indivíduos.

Esta pesquisa, parte integrante de minha formação na pósgraduação em Artes Visuais e Educação, na Universidade de Barcelona, Espanha, foi desenvolvida com um grupo de rapazes de uma instituição de apoio a pessoas com orientação sexual não-normativa, chamada Casal Lambda ${ }^{2}$. Com este grupo fixei
2. A sede social de Casal Lambda está na rua Verdaguer i Callís, $n^{\circ}$ 10. Sua direção na web é: $h t t p: / /$ www.lambda web.org. 
3. O termo queer é ambíguo e pode ter conotações negativas e

agressivas. Pode ser traduzido como raro, fora do comum, excêntrico. Desde a década de 9o,

um grupo de teóricas e teóricos começou a utilizar a palavra "queer" para descrever seus trabalhos e perspectivas teóricas.

A proposta desses teóricos é de re-significar o termo, recuperar-

lo de uma forma positiva para uma auto-identificação. "A Teoria

Queer é uma teoria sobre o gênero que afirma que a orientação sexual e a identidade sexual

ou de gênero das pessoas são o resultado de uma construção social e que, portanto, não existem papéis sexuais essenciais ou biologicamente inscritos na natureza humana, mas sim formas socialmente variáveis

de desempenhar um ou vários papéis sexuais". Fonte: Wikipédia. (http://es.wikipedia.org)

4. Sair do armário é uma expressão que significa anunciar publicamente a orientação sexual ou identidade de gênero de alguém, ou de si próprio. Estar fora do armário significa que alguém, cuja orientação é geralmente, lésbica, homossexual, transgênero ou queer, não oculta a sua orientação sexual. A "saída

do armário” é geralmente um ato voluntário, em que o próprio decide revelar à família, amigos, colegas ou quaisquer outros, a sua orientação sexual. Fonte: http://pt.wikipedia.org minha atenção para as construções das identidades de gênero, sustentando minhas observações e reflexões baseada, principalmente, nos conceitos da teoria queer ${ }^{3}$. Dessa forma, para poder investigar essas questões, os rapazes foram incentivados a falar sobre temas como a infância, a escola, os relacionamentos, suas visões de mundo, suas subjetividades, as famílias, a aceitação de suas sexualidades e, sair ou não sair do armário ${ }^{4}$.

Meu interesse foi observar como esses rapazes mediaram e negociaram seus espaços para o desenvolvimento e visibilidade de suas identidades de gênero, uma vez que, qualquer manifestação fora da heteronormatividade encontra dificuldades de ser acomodada no sistema normativo de representações e este fato constitui-se em um paradoxo, uma vez que os discursos de multiculturalidade e a construção e a aceitação das diferenças fazem parte dos conteúdos contemporâneos.

Para realizar esta pesquisa me posiciono dentro do construcionismo social que favorece as narrativas das experiências e as próprias construções de visões do mundo dos sujeitos. A técnica utilizada foi de observação ativa e atuante neste grupo específico. Também utilizei como recurso metodológico uma entrevista com características etnográficas com um dos rapazes de Casal Lambda, e teve como objetivo uma aproximação das percepções e subjetividades do entrevistado. Em esse processo, através de conversas intensas e produtivas, fomos construindo significações de como as diferenças e as identidades são representadas e em como elas são incorporadas socialmente.

\section{O processo}

Desde o início sempre estive consciente que os sujeitos não têm uma só identidade, mas sim, múltiplos referentes de identidade que se entrelaçam. A identidade não é algo inato, ao contrário, se constrói a partir de vários aspectos no qual se desenvolvem as experiências pessoais, como os contextos e os intercâmbios, os territórios de interação social e mediação, a capacidade de reinventarse, os costumes e as normas sociais.

Para ir às reuniões com o Grupo, preparava um guia para não me perder e não esquecer-me dos blocos que queria tratar com eles. No entanto, muito prontamente, percebi que o guia era útil, mas que eu não poderia ser orientada somente por ele. Era necessário deixar que as conversações seguissem um fluxo natu- 
ral e que deveria guiar-me pelos comentários e os temas que iam surgindo, em um jogo de construção de conhecimento coletivo, onde todos falam e todos reflexionam sobre o que era dito.

Questionários baseados em perguntas e respostas têm o problema de, dependendo do objeto de estudo, tornarem-se deterministas e pouco profundos, uma vez que há a tendência do pesquisador de se centrar somente nas perguntas e, o entrevistado, nas respostas, assim se perde a naturalidade da conversa e a possibilidade de construção de conhecimento em conjunto. Para essa investigação era importante estar muito atenta ao que estava sendo dito, buscar brechas, ecos, procurar acompanhar o raciocínio do entrevistado e observar suas maneiras e gestos corporais.

Neste sentido pode-se dizer que quem fala quer que o outro lhe escute e que preste atenção ao que está sendo dito, pois, talvez o mais potente de uma conversação, seja justamente a reflexão ao que se vinha falando, assim, se fala do que se 'fala' e juntos criamos possibilidades de trocas e novas formas de abordar os temas que iam surgindo.

\section{As reuniões com o Grupo de Jovens}

Durante as conversas com o Grupo observei que as identidades estão intimamente ligadas aos paradigmas culturais da sociedade e que há características que se movem entre o público e o privado. Falamos de regras impostas, de mensagens implícitas e explícitas e de como isso afeta a construção das identidades. Por muitos momentos alguns assuntos pareciam não esgotarem-se, pois ao discurso de um, nascia uma nova possibilidade de resposta, novos argumentos e novas indagações.

Prontamente o Grupo entrou em acordo que as identidades de gênero estão intimamente ligadas aos moldes de repetição, onde se aprende a desenvolver-se como homem ou como mulher pelos processos de imitação e de identificação e, quando esse modelo definido pela sociedade heterossexual não é atendido, começam os problemas uma vez que para a maioria das pessoas com sexualidade não-normativa, a visibilidade de suas identidades sexuais e de gênero são fortemente (auto)reguladas e, consequentemente, qualquer prática de subjetividade fora da heteronormatividade encontra dificuldades de ser ajustada, pois exige-se um alinhamento "normal" e coerente entre sexo, gênero e sexualidade. 
5. Áries é um pseudônimo. Durante a realização desta investigação assumi o compromisso com as pessoas envolvidas no processo de mudar seus nomes e manter-los no anonimato.

6. Neste trabalho, gay é usado como termo para definir as pessoas com práticas de subjetivações sexuais fora dos padrões da heteronormatividade.
Quando se nasce uma criança é costume dizer que ela é homem ou mulher a partir de seu órgão genital. Mas ser uma mulher ou um homem somente se inicia com o reconhecimento de si mesmo e com a construção de sua identidade pessoal em inter-relação com o social. Essa identidade é construída em um processo de identificação ou de diferenciação com as pessoas que estão ao redor, em interação com o contexto e de acordo com as experiências vividas.

\section{A entrevista etnográfica}

A entrevista foi feita a Áries 5 , 19 anos, estudante de comunicação. Este rapaz é um ator social que se encaixa perfeitamente nos objetivos desta pesquisa porque tem uma história de vida intensa, uma vez que sempre teve que viver com o fator do "diferente" na sociedade, não somente pelo fato de ser gay $^{6}$, mas também por ter um problema físico congênito que afeta suas pernas e, em consequência, seu caminhar. Este característica de Áries acrescenta outra problematização a sua vida além de sua sexualidade. Vivendo com a condição de ser diferente em uma sociedade que tem dificuldades em assimilar o "desigual", ou fazê-lo de uma forma resistente, a força de Áries está exatamente neste ponto. Lutar contra a tendência padronizante da sociedade lhe fez adquirir a necessidade de desenvolver uma espécie de anticorpos para sobreviver na floresta urbana.

A entrevista com Áries foi aberta, espontânea e intencionalmente não-diretiva. O objetivo principal, em quase duas horas e meia de conversação, foi deixar que Áries me levasse aos assuntos que lhe são importantes, seus pontos de vista sobre situações, experiências, suas emoções e as histórias que marcaram sua vida, ou parte dela.

Para alcançar esses objetivos me fixei nos seguintes pontos: ter disposição para ficar calada e escutar, ou seja, ouvir atentamente; observar os signos corporais bem como as pausas e os silêncios que também querem dizer algo; ser consciente que o entrevistado me conhece pouco e por isso desenvolver a narrativa calmamente para que Áries se sentisse relaxado, cômodo e pouco a pouco fosse ganhando confiança; e, acima de tudo, ter disposição para resistir à tentação de discordar ou dar opiniões pessoais do que estava sendo dito.

A opção por fazer esta entrevista baseada na narrativa foi por acreditar que essa forma de investigação permite dar forma às 
experiências cotidianas. Com as narrativas de vida é possível reconstruir o que passou e fazer novas resignificações e interpretações do que foi vivido. As narrativas também têm o potencial de tornar visível outras verdades. Ainda que, algumas vezes, essa estratégia de investigação possa tornar-se uma tarefa complexa, uma vez que a narrativa exige que muitos elementos atuem ao mesmo tempo em um único sujeito, como Connelly e Clandinin apontam: "a complexidade da narrativa inclui que uma mesma pessoa ao mesmo tempo viva, explica, re-explica e revive essas historias". (CONNELLY y CLANDININ, 1995, p. 22)7.

A complexidade também está no fato que, quem narra, fala de coisas que talvez ela mesma tenha dificuldades para alcançar seus significados e, além disso, algumas histórias podem não ser fáceis de serem revividas porque podem trazer à superfície antigos fantasmas perdidos em algum caos da memória.

No entanto, os relatos têm o potencial de permitir dizer quem somos, de falar sobre situações experimentadas que sinalaram e guiaram os comportamentos subsequentes e que, de alguma forma, deixaram visíveis os caminhos que decidimos trilhar. A história narrada também tem o poder de ir-se se recreando e sendo modificada com o tempo, para adequar às novas situações que o sujeito está vivendo. É um movimento constante no qual as pessoas vão (re)construindo o sentido das coisas, manejando e alinhavando resignificações. Criam novas possibilidades para entender as direções que os indivíduos elegem para seguir em frente, como explica Heather Fraser: "Narrativas de vida é uma atividade importante porque ajudam as pessoas a organizar suas experiências significativas em episódios que convoquem modos culturais de raciocínio e de representação. (FRASER, 2004, p. 180) ${ }^{8}$.

A entrevista com Áries foi rica para sinalar as histórias invisibilizadas de sua trajetória, fazer vir à superfície os traumas, os vazios e as inseguridades. Os aspectos etnográficos desta narrativa colaboraram para que ele pudesse repensar as histórias importantes de sua vida, suas escolhas e seu contexto atual.

\section{Reflexões}

O senhor... mire veja: o mais importante e bonito, do mundo, é isto: que as pessoas não estão sempre iguais, ainda não foram terminadas - mas que elas vão sempre mudando. Afinam ou

7. Tradução livre.

8. Idem. 
9. Idem

10. No cabe hacer una división binaria entre lo que se dice y lo que se calla, habría que intentar determinar las diferentes maneras de callar, cómo se distribuyen los que pueden y los que no pueden hablar, qué tipo de discurso es autorizado o qué forma de discreción es requerida para los unos y los otros. No hay un silencio sino silencios varios y son parte integrante de estrategias que subtienden y atraviesan los discursos. (FOUCAULT, 2006, p. 28). desafinam. Verdade maior. É o que a vida me ensinou. Isso que me alegra, montão. (ROSA, Guimarães. Grande Sertão: Veredas, 2006, p. 20)

Neste fragmento de "Grande Sertão: Veredas", Rosa ressalta a forma como transitamos e reconstruímos nossas identidades. Nesta direção este projeto propôs refletir sobre as construções de gênero e de identidade sexual de pessoas que se encontram fora dos padrões da heteronormatividade. Este projeto também quis pensar a diversidade de subjetividades apontando para a variedade de tecnologias do "eu" que questionam os 'gêneros inteligíveis', termo usado por Butler (2001, p.70), para definir os gêneros que dão continuidade e coerência entre sexo, gênero, desejo e as práticas sexuais, enquanto algumas rupturas e novas inserções contestam a mesma escala de inteligibilidade.

Durante o processo de desenvolvimento desta pesquisa baseiome na perspectiva do construcionismo social, nos estudos culturais e na teoria queer, que ofereceram os suportes para re-pensar os conceitos deterministas que orientam as atitudes dos grupos sociais, em especial a teoria queer, que propõe "romper com os espaços fixos e finitos da identidade", levando em conta que "a sexualidade não tem significados a priori, mas significados relacionais que se constroem, se imitam e são imitados". (TALBURT, 2005, p. 25).9

Nas bases das principais formulações queer se situa a teoria do poder de Michel Foucault que problematizou o biônimo sexo/ natureza, pensando o sexo por uma ótica histórica e culturalmente construída. Esta pesquisa é coerente com esta proposta, sobretudo na seguinte afirmação do filósofo:

Não cabe fazer uma divisão binária entre o que se disse e o que se cala, haveria de tentar determinar as diferentes maneiras de calar, como se distribuem os que podem e os que não podem falar, que tipo de discurso é autorizado ou que formas de discrição é requerida para uns e outros. Não há um silencio, mas silêncios vários e são parte integrante de estratégias que subentendem e atravessam os discursos. (FOUCAULT, 2006, p. 28, tradução minha)..$^{10}$

Segundo os teóricos queer se faz necessário romper com essa lógica binária e, consequentemente, com seus efeitos: a hierarquia, a classificação, os estigmas, a dominação, o abuso do poder e a exclusão. Para esta corrente teórica, a heterossexua- 
lidade e a homossexualidade são elementos interdependentes, mutuamente necessários e fazem parte de um mesmo padrão de referencias, Guacira Louro coloca dessa forma esta questão:

A afirmação da identidade implica sempre a demarcação e a negação de seu oposto, que é constituído como sua diferença. Este "outro" permanece, no entanto, indispensável. A identidade negada é constitutiva do sujeito, fornece-lhe o limite e a coerência e, ao mesmo tempo, assombra-o com a instabilidade. (LOURO, 2004, p.45)

Os conceitos da teoria queer ajudam a entender como foram estabelecidas as normas universais da sociedade e em como é possível pensar em estratégias que podem melhorar os conflitos provocados pela diversidade de gêneros, uma vez que esses teóricos acreditam que o social é um contexto que pode ser interpretado e criticado com o objetivo de contradizer o conhecimento e as hierarquias de dominação. Também sugere novas formas de pensar a cultura, o conhecimento, o poder e a educação, neste sentido, a afirmação de Silva:

A teoria queer aplica a hipótese da construção social ao domínio da sexualidade. Não são somente as formas por as quais aparecemos, pensamos, atuamos como homem e mulher nossa identidade de gênero - as que são socialmente construídas, mas também as formas por as quais vivemos nossa sexualidade. (SILVA, 2001, p. 130, tradução minha) ${ }^{11}$

Minha inquietude está no fato que penso que as transformações sociais e seus efeitos, principalmente nos entornos urbanos, precisam ser analisados em profundidade uma vez que essa dinâmica modifica a visão sobre os sujeitos e gera novos sentimentos de identidade, sempre em trânsito, nos relacionamentos sociais. No entanto, essas transformações podem adquirir tonalidades de estigmatização e discriminação nas pessoas que não se enquadram aos discursos da heteronormatividade. Neste contexto, esses mesmos sujeitos não constituem parte da realidade dessas mudanças culturais? Como é possível destigmatizar os preconceitos que enfrentam as pessoas que têm outras práticas sexuais que não sejam aquelas socialmente aceitadas? De quê forma podemos pensar as representações de gênero e de diversidade sexual de uma forma plural, ampliada e em constante movimento?

São questões emergentes relacionadas com a contemporaneidade e que se aproximam dos problemas relacionados com a identidade,
11. La teoría queer aplica la hipótesis de la construcción social al dominio de la sexualidad. No son sólo las formas por las cuales aparecemos, pensamos, actuamos como hombre y mujer nuestra identidad de género - las que son socialmente construidas, sino también las formas por las cuales vivimos nuestra sexualidad. (SILVA, 2001, p. 130) 
12. Por eso es importante plantear lo que distingue la subjetividad de una persona de su identidad respecto a un grupo. Cada individuo tiene una percepción de sí mismo que puede o no ser coincidente con la que otros individuos o diferentes grupos, tienen sobre él o ella. Las discrepancias entre la propia subjetividad y la identidad grupal es causa de preocupación y ansiedad en la gente joven. Lo que lleva con frecuencia a que la identidad del grupo se privilegie sobre la experiencia de ser individual. (HERNÁNDEZ, 2007, p.7o) a diferença, igualdade e alteridade. É necessário pensar maneiras de desfazer conceitos e práticas que fazem parte do 'sentido comum ', impregnado no imaginário social e cultural, nos discursos institucionais e nos meios de comunicação, que foram gradualmente incorporados e consumidos como legítimos e universais.

Entendo que a sociedade tem claros problemas para acompanhar as transformações que são produzidas cada vez mais rapidamente nos grupos sociais, mas não há como fingir que existem pessoas que não se adaptam ao discurso binário das identidades sexuais. A identidade de gênero não é fixa, mas sim instável, as pessoas transitam em suas identidades e as subjetividades não são construídas de maneira homogênea, não há como situar um sujeito sem levar em conta suas conexões com o mundo, os processos históricos e as condutas sociais, como nos recorda Fernando Hernández:

Por isso é importante ressaltar o que distingue a subjetividade de uma pessoa de sua identidade a respeito de um grupo. Cada individuo tem uma percepção de si mesmo que pode ser ou não ser coincidente com a que outros indivíduos o diferentes grupos, têm sobre ele ou ela. As discrepâncias entre a própria subjetividade e a identidade grupal é causa de preocupação e ansiedade nas pessoas jovens. O que leva, com freqüência, que a identidade do grupo se privilegie sobre a experiência do ser individual. (HERNÁNDEZ, 2007, p.7o, tradução minha) ${ }^{12}$

Falar sobre sexualidade e diferenças de identidades sexuais é, contudo, uma tarefa difícil na maioria dos espaços demarcados. Há uma tendência em ocultar estrategicamente qualquer fato ou evidência que extrapole e/ou perturbe o ambiente normativo onde transitamos. Não é comum tratar as questões das identidades sociais através do território da multiplicidade, do dinamismo, da fragmentação e da contradição.

A heterossexualidade segue sendo o padrão que impõe a conduta ideal das identidades sexuais e, como não podia ser diferente, a família, os processos de ensino, os discursos institucionais e as práticas do cotidiano são os pilares que conduzem, ditam e normalizam os papéis e as regras sexuais. No entanto, contraditoriamente, a homossexualidade, a bissexualidade, os interssexuais, os travestis, o transformista, a androgenia e a ambivalência, são sujeitos cada vez mais visíveis, mas, ainda, marginalizados nos lugares onde circulam, mediam e estabelecem suas relações. 
Toda essa diversidade de identidades e transformações nas práticas de subjetividades nos força a ter que elaborar outras formas de pensar o mundo. São manifestações que claramente não se esgotam no sexo biológico ou em uma herança genética, uma vez que basta sair às ruas e observar que cada vez é mais freqüente encontrar pessoas cujas identidades de gênero não estão diretamente relacionadas com a identidade sexual, ou de corpo, ou de performance.

No entanto, mesmo com tanta globalização e desenvolvimento dos meios de comunicação, os preconceitos e a discriminação permanecem vivos e latentes. O repúdio ao que é diferente gera muitos problemas às pessoas fora da heteronormatividade uma vez que têm que crescer, desenvolver-se e construir-se em um mundo com poucas características de identificação, o que torna a auto-aceitação de sua sexualidade algo ainda mais difícil, como aponta Nick Stanley:

Homossexuais nascem no meio de outros; eles possuem nomes heterossexuais; não têm uma característica que possa ser identificada, e eles aparecem aleatoriamente em todas as gerações. E cada criança homossexual irá aprender os rituais de negação, de não aceitação pessoal e de sua aparência. Então a maioria dos jovens LGBT tem uma escolha decisiva entre a auto-identificação ou manterem-se escondidos de suas famílias, parceiros, e, algumas vezes, escondidos inclusive de seus próprios possíveis futuros. (STANLEY, 2007, p. 4, tradução minha) ${ }^{13}$

Na verdade, ser diferente gera demasiada ansiedade. Pude perceber isso com o Grupo de Jovens da instituição Casal Lambda e, também, certo traços comuns nas subjetividades destas pessoas e no desenvolvimento de suas sexualidades, tais como:

a) Em geral, todos concordaram que se percebiam distintos dos demais desde pequenos.

b) A fase da adolescência é a etapa em que se iniciam os relacionamentos sociais, as primeiras mudanças e questionamentos, e as primeiras experimentações com outros dos quais se sentem identificados. É o inicio das múltiplas fases de construção de identidade de gênero, no entanto, para a sociedade e a família, continuam a passar como heterossexuais.

c) Depois há uma fase de revelar sua identidade de gênero às
13. Homosexual are born in the midst of the other; they have the names of heterosexuals; they have no identifiable characteristics, and they appear randomly in every generation. ... And every homosexual child will learn the rituals of deceit, impersonation and appearance. So most LGBT youngsters have a profound choice, whether to identify $y$ themselves or to remain hidden from their families and their peers, and, often, hidden from their own possible futures.

(STANLEY, Nick. 2007, p. 4) 
14. Es lo que pasa cuando los

valores no cumplen con los requisitos que piden: ser varonil y masculino. En cambio los chavales que no son así, que no son masculinos y fuertes, pues entonces son los cabrones, o maricas, otras cosas. Los hombres sufren mucho porque siempre tienen que estar ahí, en ese papel, no solamente los homosexuales,

los chicos que no quieren ser exactamente este héroe, este héroe que todo mundo se imagina, eses pasan muy mal.

15. Lésbicas, Gays, Bissexuais, Transgêneros, Queers e Intersexuais. pessoas importantes de seu entorno familiar e social. As famílias, em geral, não aceitam bem e, obviamente, a não aceitação é algo que incomoda e causa danos.

d) Sair do armário é algo feito com cuidado e critérios.

O grupo de Casal Lambda, quase em sua totalidade, aponta as dificuldades das famílias em aceitar suas práticas de subjetividades referentes às suas sexualidades. Isso é um espelho da sociedade em que os códigos, signos e comportamentos devem seguir regras e papéis bem demarcados. A sociedade heterossexual está determinada por preceitos que têm a função de ordenar as pessoas e as prá ticas sexuais, é um esforço para manter tranquilo um estado de coisas que põe ordem ao que é considerado normal e adequado. Se essas regras não conseguem cumprir-se há uma impressão de que algo está fora de lugar, como explica um dos rapazes de Casal Lambda:

É o que ocorre quando os valores não se cumprem com os requisitos que se pedem: ser varão e masculino. Então, os rapazes que não são assim, que não são masculinos e fortes, são etiquetados como bichas, maricas e outras coisas. Os homens sofrem muito porque sempre têm que estar aí, neste papel, não somente os homossexuais, mas os garotos que não querem ser exatamente este herói, este herói que todo mundo imagina, estes passam muito mal. (Tradução minha) ${ }^{14}$

Na configuração da construção da identidade as estratégias de poder, os aspectos socioeconômicos, culturais e os aspectos temporais também atuam com igual importância. Ainda que a sociedade heterocêntrica resista a aceitar a diversidade, é essencial encontrar formas de combater os preconceitos que ameaçam a convivência pacífica e respeitosa na sociedade, mas, em paralelo e simultaneamente, também é imprescindível identificar e combater as formas silenciosas de segregações específicas, que afetam, principalmente a alguns grupos sociais, como por exemplo, o grupo LGBTQI ${ }^{15}$.

Penso que a escola tem um papel fundamental nesse cenário de construção da tolerância e creio também ser possível incluir na pauta dos conteúdos curriculares valores como alteridade e o respeito ao diferente. É importante ensinar as meninas e aos meninos o respeito às diferenças, sejam elas quais forem, porque atitudes contra a segregação ou o menosprezo devem ser intro- 
duzidas desde cedo na formação das crianças. Os processos de ensino devem indicar o caminho do respeito a si mesmo e ao outro, partindo do reconhecimento das diferenças, que é um dos caminhos possíveis para outras alteridades. A sociedade será o principal beneficiário do fortalecimento de valores como a igualdade e a tolerância, como elementos intrínsecos de uma cultura democrática e politicamente evoluída.

É necessário desenvolver práticas educativas que contemplem as distintas modalidades das sexualidades humanas, favorecendo a integração progressiva no modus vivendus de nossa sociedade das pessoas que estão à margem dos padrões da heteronormatividade, porque a não-normatividade hoje, não implica na conformidade de amanhã, e terminará por ser vista de uma forma menos marginal, mas sim, apenas como outra forma de ser e de estar no mundo.

\section{Referências Bibliográficas}

BUTLER, J. El género en disputa. El feminismo y la subversión de la identidad. Barcelona: Ed. Paidós, 2001.

CONNELLY y CLANDININ. Relatos de experiencias e investigación narrativa, in LARROSA, y otros. Déjame que te cuente. Ensayos sobre narrativa y educación. Barcelona: Laertes, 1995.

FOUCAULT, Michel. Historia de la Sexualidad: la voluntad de saber, v. 1. Madrid: Ed. Siglo XXI de España, 2006.

FRASER, Heather. Doing Narrative Research: Analysing Personal Stories Line by Line. Qualitative Social Work, vol. 3, n. 2, 2004, p. 179-201.

HERNANDEZ, Fernando. Espigador@s de la cultura visual. Barcelona: Octaedro, 2007.

LOURO, Guacira L. Um corpo estranho - ensaios sobre sexualidade e teoria queer. Belo Horizonte: Ed. Autêntica, 2004.

ROSA, J. G. Grande Sertão: Veredas. Rio de Janeiro: Ed Nova Fronteira, 2006. 
SILVA, Tomaz T. Espacios de identidad: nuevas visiones sobre el curriculum. Barcelona: Ed. Octaedro, 2001.

STANLEY, Nick. 'Anything You Can Do': Proposals for Lesbian and Gay Art Education. JADE 26.1, 2007, p. 2-9.

TALBURT, Susan y STEINBERG, Shirley R. (eds.) Pensando Queer: Sexualidad, cultura y educación. Barcelona: Ed. Graó, 2005 . 
Licenciada em Artes Visuais pela Universidade Federal de Goiás. Doutoranda em "Artes Visuais e Educação" pela Universitat de Barcelona, Facultat de Belles Arts, Espanha. Pesquisa as questões de gênero e de sexualidade não normativas.

E-mail: carlaluzia@gmail.com 